\title{
Static Friction in Oil Lubricated Cold Forming Processes
}

\author{
Wilhelm Schmidt ${ }^{1} \oplus \cdot$ Philipp Heck $^{1} \cdot$ Christoph Gaedigk $^{1} \cdot$ Peter Groche $^{1}$
}

Received: 26 August 2021 / Accepted: 15 December 2021 / Published online: 4 January 2022

(c) The Author(s) 2022

\section{Abstract}

Friction is one of the variables that have a far-reaching influence on forming processes. In the past, less attention was paid to static friction than to sliding friction in forming processes. In this paper, a test stand for the determination of static friction under load in metal forming is presented. The results are discussed using the example of an oscillating cold forming process. It could be shown that the expected influence of static friction is low in this application.

\section{Graphical abstract}

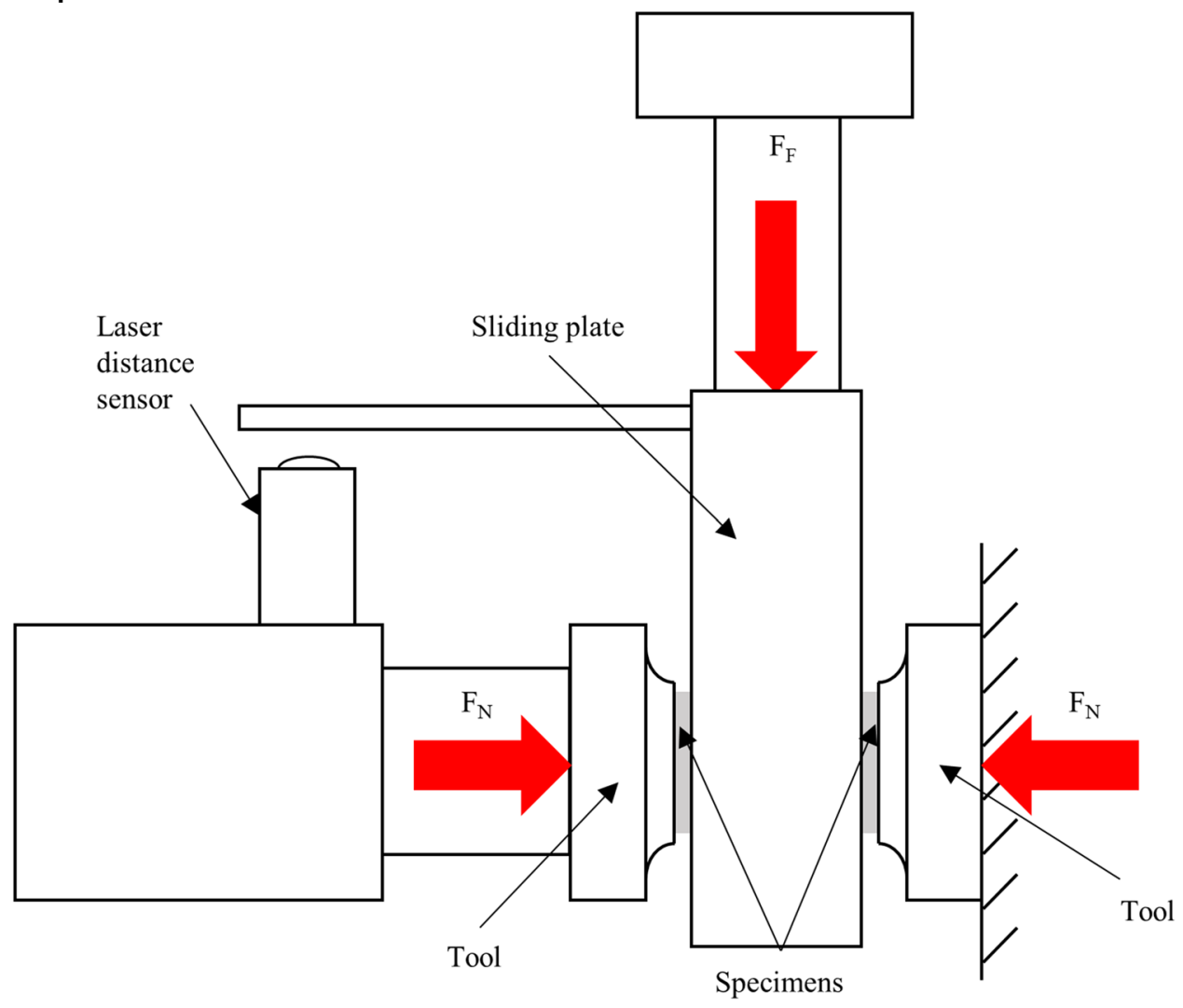

Keywords Static friction $\cdot$ Stick-Slip $\cdot$ Stiction $\cdot$ Forming $\cdot$ Cold forging $\cdot$ Friction test methods

Wilhelm Schmidt

wilhelm.schmidt@ptu.tu-darmstadt.de

1 Institute for Production Engineering and Forming Machines,

Technische Universität Darmstadt, Darmstadt, Germany 


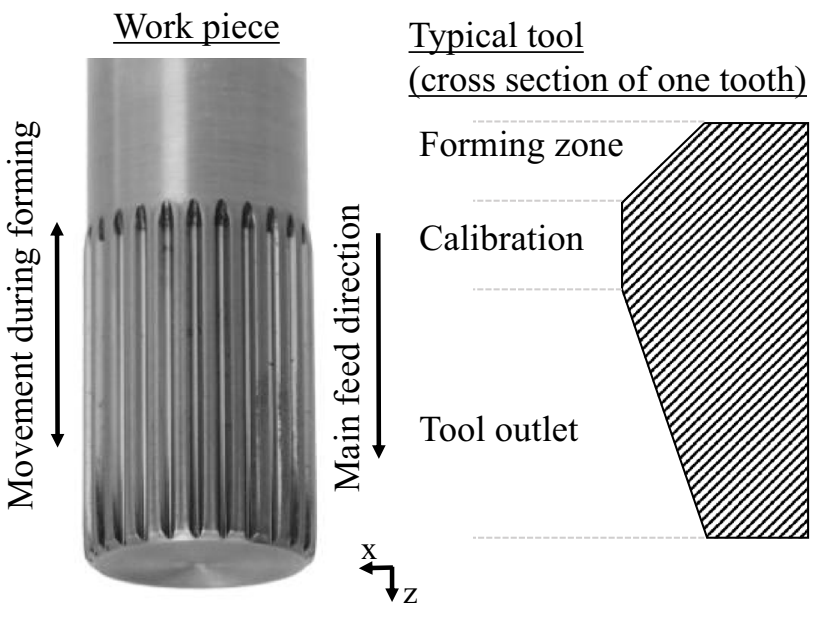

Fig. 1 Work piece produced with oscillating gear forming process and cross section of one tooth of the tool

\section{Introduction}

Friction has decisive effects on forming processes [1]. In order to quantify this influencing factor, there is a multitude of tribometers which describe sliding friction, which occurs when two contact bodies move relative to each other.

Da Vinci already measured static friction. The experimental setup was reported on and was rebuilt. A suspended rope linked to a test mass $M_{F}$ is guided over rolling elements onto a static plane with a sliding block with a defined mass $M_{N}$. Various test masses $M_{F}$ are hooked onto the rope. As soon as the weight is large enough, the block is set in motion. Based on the weights, the friction value at which the movement begins, is calculated [2]. This results in the stick-slip condition: $\left|F_{F}\right| \leq \mu_{s} F_{N}$, where $\mu_{s}$ is the static friction coefficient, if the formula is satisfied. $F_{F}$ is defined as the friction force and $F_{N}$ as the normal force [3].

Oscillating forming processes in which static friction occurs during the change of direction, are potentially strongly influenced by this phenomenon. An example of these processes is oscillating gear forming, in which the gear teeth are produced by an oscillating movement of the tool or component. Figure 1 shows a typical formed work piece and a schematic tooth of a tool, usually made of hard metal. Forming with tools made of conventional steel (1.2379/AISI D2) and without coating is also possible, but leads to faster wear [4]. During forming the forward stroke is longer than the return stroke. Due to the oscillating movement, relubrication with oil can improve the contact condition in the forming zone, which can significantly reduce the forming force compared to unidirectional movement [5].

The calibration zone slides on the already formed surface during forward and return stroke. Numerical simulations show that a contact normal stress of 1200 to $1800 \mathrm{~N} / \mathrm{mm}^{2}$ can be found in this area [6]. Therefore, this zone is potentially strongly influenced by friction conditions and especially static friction.

In the past, various strategies have been used to determine or describe static friction. In the following, analytical, numerical and experimental approaches are briefly summarized:

Tabor presented the state of the art of friction in 1981, referring to the work of Coulomb and Euler, among others. According to this, friction during sliding is usually less than static friction because 'asperities on one surface could jump part of the way over the gap between asperities on the other' [7].

Asperity was also a central topic for Bay and Wanheim, when they investigated friction under high loads. The study focused on the true contact area, but it was also possible to detect the effects of static friction at the beginning of the test. A drop from higher static friction (static friction peak) to sliding friction was observed, followed by an increase in sliding friction with rising sliding length. A statement about the height or the origin of the static friction peak remains open [8].

Chang et al. described the static friction in a mathematical model using surface mechanics approaches, where they also referred to asperities. The calculation includes the influence of the contact normal load on the shear strength of the interfacial junctions [9].

In 1971, Rabinowicz examined various material pairings and measured 210 static friction coefficients. He made these observations on a tilting plane [10]. Hurtado and Melkote presented a test stand capable of detecting movements in the submillimeter range at dynamic loads of up to $300 \mathrm{~N}$ [11]. The specimens used in the test stand had a surface area of $1488 \mathrm{~mm}^{2}$ at the contact area. This results in an average stress of about $0.202 \mathrm{~N} / \mathrm{mm}^{2}$ which is far below typical conditions in metal forming.

A more recent publication by Hanaor et al. describes static friction at fractal interfaces. The authors were able to calculate static friction values with a contact mechanics approach [12].

In summary, there are no measurements and test rigs to measure static friction under contact normal stresses in the plasticity range of steel with a sufficient accuracy to detect the detachment. It is a great challenge to measure static friction under the loads of forming processes. The challenge is that, on the one hand, very high contact normal stresses must be applied and, on the other hand, minimal movements must be detected.

The aim of this work is to quantify static friction for forming processes and the effects on the gear forming process under oil lubrication. Since asperities were a key parameter for both Wanheim and Bay in their studies, as 
well as for Chang et al. and Hanaor et al. in their calculations, it is necessary to include surface structure as an influencing parameter into the study.

To measure static friction with contact normal stresses above $1000 \mathrm{~N} / \mathrm{mm}^{2}$, a new test rig was developed. In the following, this test rig will be presented. After explaining the evaluation methodology, various surfaces and test procedures of the static friction tests are presented and discussed.

\section{Test Rig and Setup}

The test stand is based on the principle of a sliding plate which is clamped from two sides. The schematic test setup is shown in Fig. 2. As can be seen, the sliding plate is clamped horizontally between two deformable specimens. There is no further guidance to avoid bearing friction.

The test stand has been designed for a Zwick Roell tensile/compression testing machine that can apply forces of up to $100 \mathrm{kN}$. This press provides the friction force $F_{F}$ during the test. Since a second actuator is needed to apply the normal force $F_{N}$, a hydraulic cylinder is used to apply the normal force from one side.

The test assembly is housed in a frame, therefore the same force is generated by the reaction force $F_{N}$. Hydraulic pressure adjustment allows the cylinder to apply a defined normal force. In order to examine the detachment accurately, a precise position measurement is necessary. A laser triangulation sensor LK-H027 from Keyence Corporation observes the movement of the sliding plate.

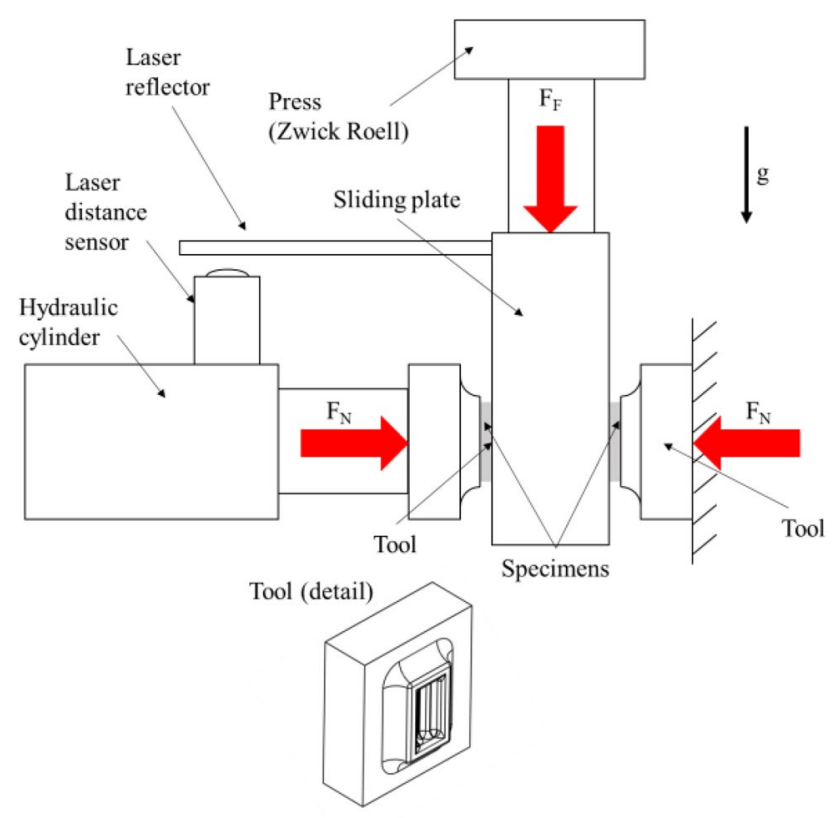

Fig. 2 Schematic illustration of test rig

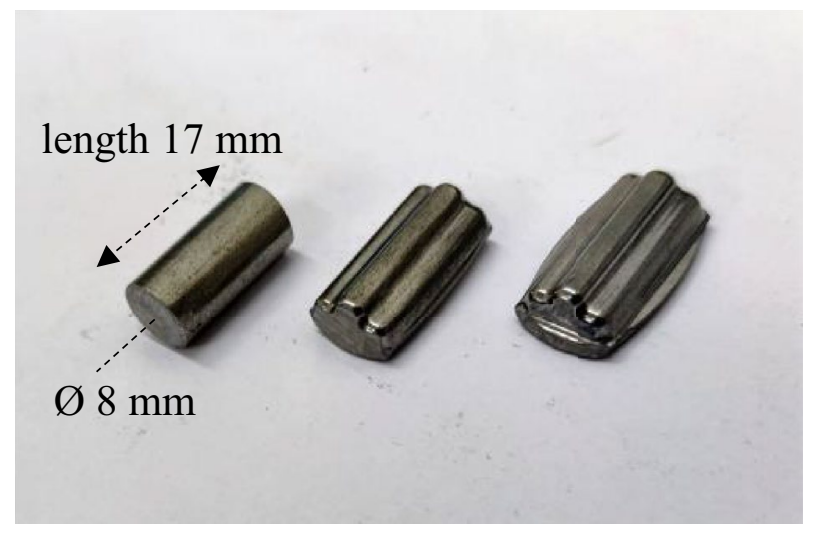

Fig. 3 Specimen initial (left), compressed at $150 \mathrm{kN}$ (middle), compressed at $250 \mathrm{kN}$ (right)
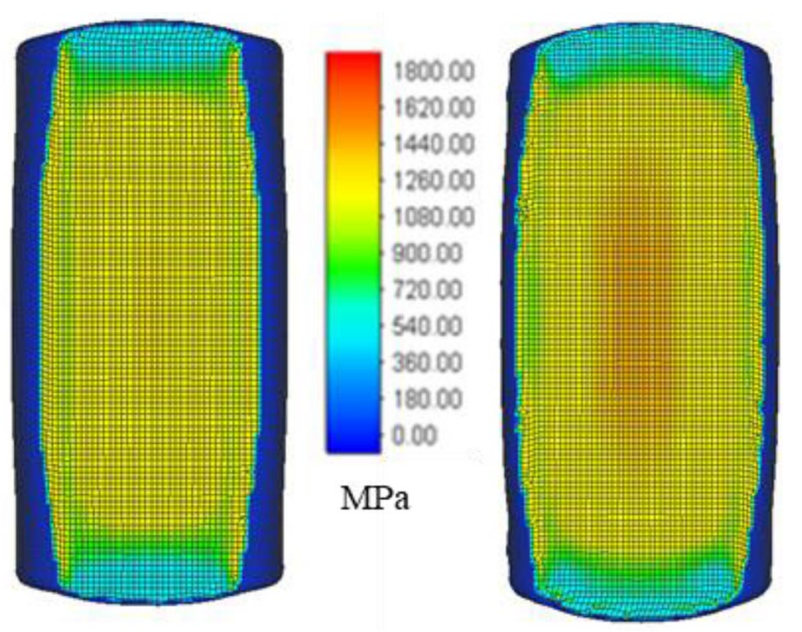

Fig. 4 Contact normal pressure of the sliding surface of the specimen. Contact normal force: Left $150 \mathrm{kN}$, right $250 \mathrm{kN}$

The specimens are cylindrical in the initial state and are compressed and shaped in horizontal direction, see Fig. 3. This shape was developed for the tribometer Sliding Compression Test (see also [13]) to generate high stresses and to ensure that the specimen is mounted in the upsetting tool during the sliding movement. The initial length of the specimen is selected at $17 \mathrm{~mm}$ so that the mold is completely filled and the specimen cannot move in the tool during the test.

The tests are performed at $150 \mathrm{kN}$ and $250 \mathrm{kN}$ normal force. The contact stresses as they occur at the flat contact surface between specimen and sliding plate are shown in Fig. 4. The contact normal pressure between specimen and sliding plate reaches in a numerical simulation about $1400 \mathrm{~N} / \mathrm{mm}^{2}$ for the test with $150 \mathrm{kN}$ and up to $1600 \mathrm{~N} / \mathrm{mm}^{2}$ for the test with $250 \mathrm{kN}$ contact normal force. As work piece material $16 \mathrm{MnCrS} 5 / 1.7131$ (AISI $5115, R_{p} 0.2=695 \mathrm{~N} /$ 
$\mathrm{mm}^{2}$ ) has been chosen. It is commonly used in the industry for cold forming processes. This material is in drawn condition and therefore corresponds to the delivery condition of many industrial forming processes. The initial surface topography of the specimen is $S_{a}=0.716 \mu \mathrm{m}$. Surface measurements were performed with Nanofocus $\mu$ Surf-expert confocal microscope (magnification 20x) and evaluated with MountainsMap software by Digital Surf. The specimen has an initial hardness of 192 (standard deviation $\sigma=9.2$ ) HV 10 . Specimens formed with $150 \mathrm{kN}$ show a hardness of 226.0 $(\sigma=4.08) \mathrm{HV} 10$. After tests with $250 \mathrm{kN}$ a hardness of $259.33(\sigma=2.35)$ HV10 can be measured. The tool and sliding plate are made of the material 1.2379 (AISI D2) with an average hardness of $604(\sigma=16.3)$ HV5. Different plates were used for the test: Sandblasted $\left(S_{a}=0.359 \mu \mathrm{m}\right)$, ground in sliding direction $\left(S_{a}=0.354 \mu \mathrm{m}\right.$, measured in sliding direction $\left.R_{a}=0.325 \mu \mathrm{m}\right)$ and polished surfaces $\left(S_{a}=0.023 \mu \mathrm{m}\right)$. No macroscopic wear was visible on the plates or the specimens. The plates were prepared (polished, ground or blasted) when the normal force has been varied. The surface of the tool was not varied, as there will be no relative movement between the forming tool and the specimen.

The commercial forming oil Multidraw CF4 by Zeller +Gmelin, is applied as the lubricant. The specimens were dipped in oil, dripped off before each test and placed on the pre-oiled plate.

The tests were carried out in two different ways. In variant one, the press is programmed force-controlled. The force increases by $1 \mathrm{kN}$ per second. In variant two, the press is programmed in a path-controlled manner. In this mode, the speed is set to constant $0.5 \mathrm{~mm} / \mathrm{s}$.

Specimens were formed immediately before the test. To keep external influences to a minimum, less than $1 \mathrm{~min}$ passes between the forming of the specimen and the start of the static friction test in both cases. Tests were also carried out with previously deformed specimens. These specimens were also dipped in oil again before testing.

\section{Evaluation and Results}

The evaluation of the results is based on the force and displacement measurements. These are shown in the following figures plotted over the test duration. Force measurements are represented by continuous lines, displacement curves by interrupted lines. This notation will be kept throughout the paper. The reproducibility can be classified as high and can be seen later from the error bars in Figs. 10 and 11. The following section presents the evaluation methodology, which leads to these results.

Figure 5 shows an experiment with force control (variant 1). The static friction force increases until the

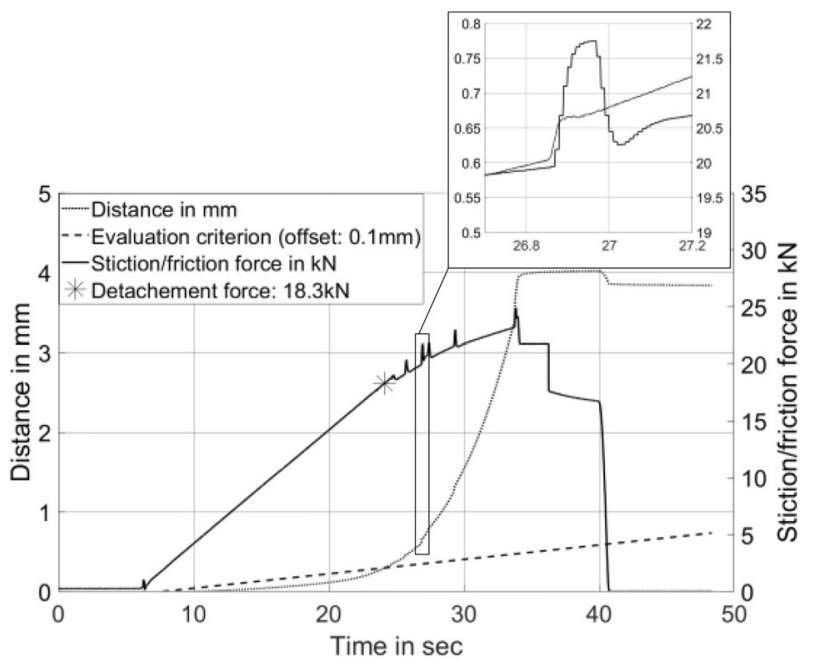

Fig. 5 Changes in distance and stiction/friction force $F_{F}$ in case of constant increase of force $1 \mathrm{kN} / \mathrm{s}$, normal force $F_{N} 150 \mathrm{kN}$, without forming, sandblasted surface

detachment occurs. At this moment $(18.3 \mathrm{kN})$, the gradient of the position measurement (laser distance sensor in Fig. 2) changes because a relative movement takes place. The movement measured before detachment is due to the elastic deformation added between the sliding plate, specimen, punch and insulating insert.

After this initial detachment, the force $F_{F}$ continues to increase with $1 \mathrm{kN}$ per second until the end of the test is reached. This increase in force is part of the test procedure for variant 1 . During this time, scattering in the force measurement of some tests can be observed. This effect is most probably based on adjustments of the press force control due to stick slip. If the force does not increase at $1 \mathrm{kN}$ per second due to slipping, the process force is quickly increased by the press control. At the end of the slipping, the press regulates off again. Figure 5 shows also a detailed section of this effect.

The elastic deformation is used as evaluation criterion. The slope of the displacement curve is calculated between 0.1 and $0.15 \mathrm{~mm}$ (elastic) displacement. The evaluation line is $0.1 \mathrm{~mm}$ parallel to this initial slope. This ensures that small movements are detected and that the detection is still robust. This line is extrapolated and plotted as a dashed line in Fig. 5. As soon as the position measurement crosses the evaluation line, this point is interpreted as the detachment point.

Figure 6 shows a test result carried out with variant 2, the position control. Due to the controller of the Zwick test bench, the force increases rapidly in the position control mode. Here it is visible that the position measurement changes at the moment of detachment and crosses the dotted line, as previously explained. 


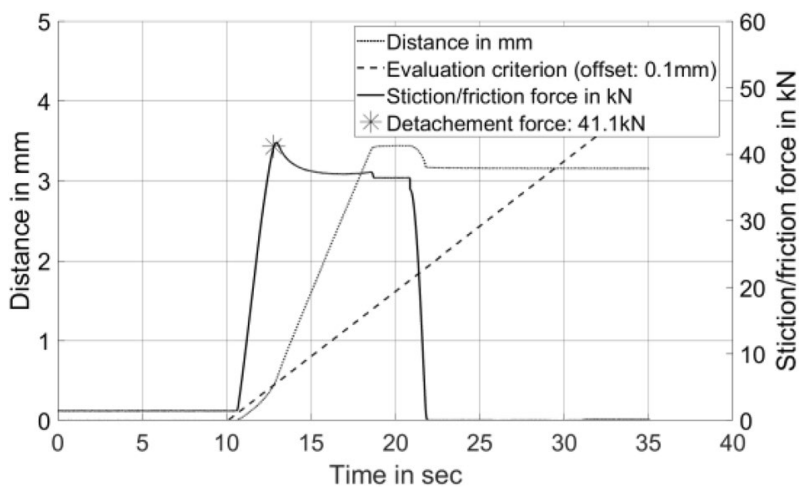

Fig. 6 Changes in distance and stiction/friction force $F_{F}$ in case of constant velocity $0.5 \mathrm{~mm} / \mathrm{s}$, with forming, sandblasted surface, $F_{N}$ $150 \mathrm{kN}$

The position control in variant 2 results in a static friction peak.

Variant 1 is better adapted for parameter variation, as the slow increase in force allows the detachment to be observed precisely. In contrast, variant 2 is more suitable for comparing static and sliding friction, since sliding at constant velocity occurs after detachment.

Scattering was observed during tests of variant 1 , which can be explained by the press control, as explained above. This effect is not seen during the position controlled tests (variant 2). Depending on the application, it must therefore be decided whether the force or the position control should be used for the respective test.

In the following, the tests with variant 1 are first varied for different parameters before the results for variant 2 are discussed.

\subsection{Results: Variant 1}

In the first step, the influence of a forming operation on the static friction value is examined. Here, the behavior of a specimen that is formed during the test will be compared to the detachment behavior with a preformed specimen. The preformed specimens have passed a complete test with forming and sliding with the same loads before being placed in the test rig a second time. The preformed specimens represent the calibration section during oscillating gear forming process, since they have also already been formed and have undergone a relative motion when oscillation occurs. Figure 7 shows the result of a test with a ground surface.

As a result, the test performed without forming moves at a lower friction force than a test with forming. Causes for this are a leveling of the roughness (see Fig. 15) or the thinning of the lubricating film, as explained for sliding friction in a previous paper [5].

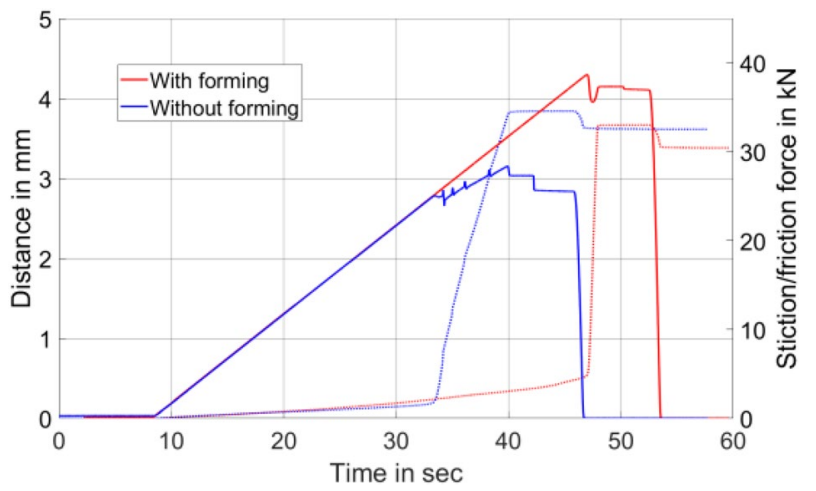

Fig. 7 Comparison of changes in distance and stiction/friction force $F_{F}$ between with and without forming of workpiece (normal force $F_{N}$ $150 \mathrm{kN}$, ground surface; ground in sliding direction

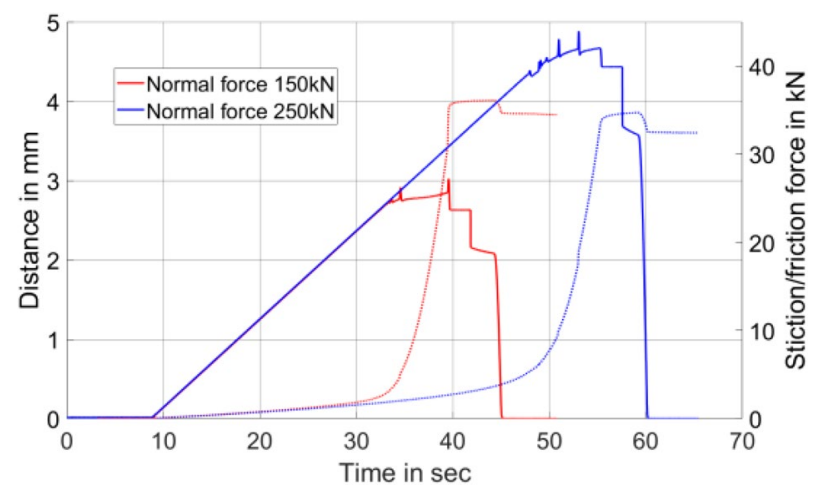

Fig. 8 Comparison of changes in distance and stiction/friction force $F_{F}$ with different normal forces $F_{N}$ (with forming, polished surface)

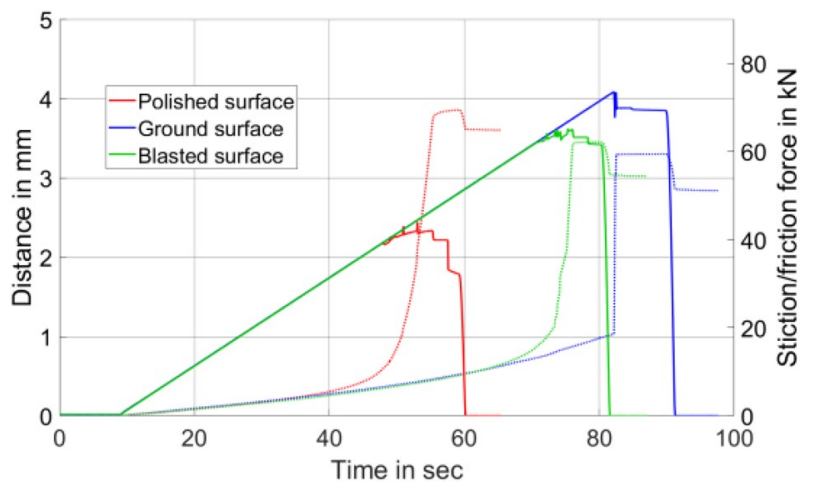

Fig. 9 Comparison of changes in distance and stiction/friction force $\mathrm{F}_{\mathrm{F}}$ with different surfaces (normal force $F_{N} 250 \mathrm{kN}$, with forming)

In addition, the contact normal stress was varied. This results in the changes being observed as shown in the Fig. 8 for the polished surface with forming operation. The higher normal force has an effect on later detachment of the friction partners from each other.

The test results, shown in Fig. 9, were performed with the three surfaces explained above. The graph shows the 


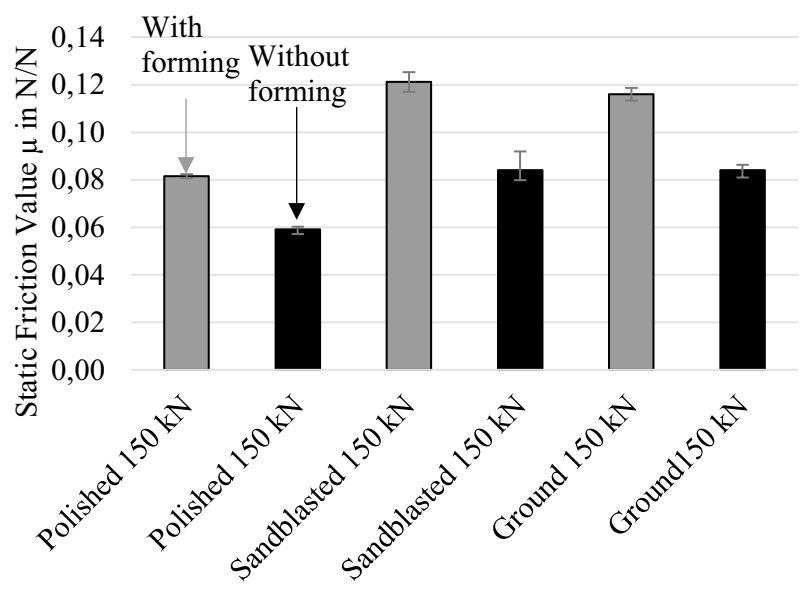

Fig. 10 Static friction coefficient (normal force $F_{N} 150 \mathrm{kN}$ )

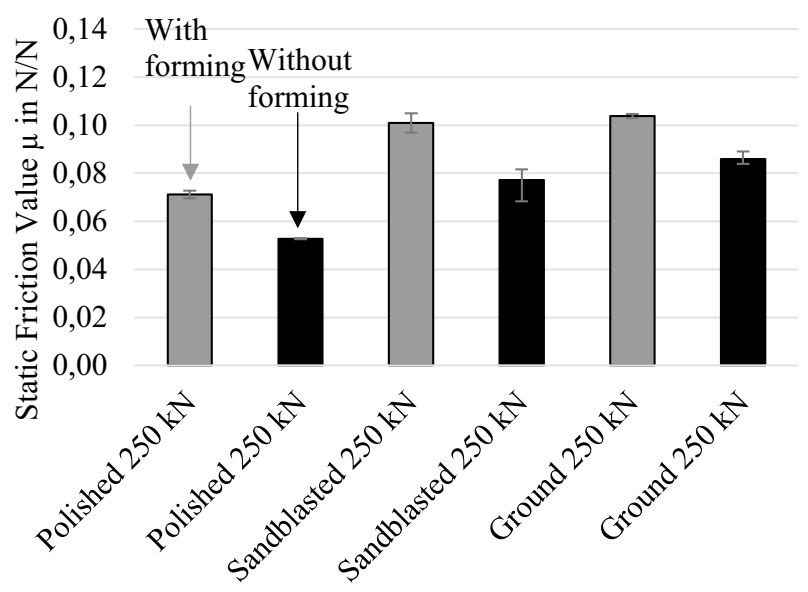

Fig. 11 Static friction coefficient (normal force $F_{N} 250 \mathrm{kN}$ )

test results for polished, blasted and ground surfaces with $F_{N}=250 \mathrm{kN}$. Detachment occurs significantly earlier on polished surfaces, which can be explained by the lower hooking of the asperities of the surfaces.

Figures 10 and 11 show a summary of the stiction coefficient for variant 1 with both loads and the three different surfaces. The black bars depict the stiction coefficient without forming. All tests were performed three times. The static friction coefficient is determined by $\mu_{S}=0.5^{*} F_{F} / F_{N}$. Therefore, the forces were determined in the moment of detachment. Since there is no twisting of the plate, it is assumed that the static coefficient of friction is identical on both sides.

This confirmed the observation made before: the static friction coefficient is higher in tests with deformation (grey) compared to tests with already deformed specimens (black). Furthermore, the static friction coefficient decreases with increasing normal stress. The effect is most significant in the tests with the polished tool.

\subsection{Results Variant 2}

In variant 2 , the influence of the velocity on the static friction factor was observed. Figures 12, 13 and 14 show the coefficient of friction plotted over the sliding distance. The friction/stiction coefficient is determined using $\mu_{S}=0.5^{*} F_{F} / F_{N}$. The linear increase during the first $0.3 \mathrm{~mm}$ is based on the elastic behavior of the test rig. The depicted tests were performed with $150 \mathrm{kN}$ for all three surfaces. The first specimen (velocity $0.5 \mathrm{~mm}$ ) was formed during the test, all the other tests were performed with the same, already formed specimen. This is done to compare the set with forming and without forming also for this variant. Due to the small error bars in Figs. 10 and 11 it is not to be expected that wear will occur in the tribological system, which would make a repetition with the same specimen impossible.

Experiments with forming $(0.5 \mathrm{~mm} / \mathrm{s})$ show higher coefficients of friction. The results of the tests without forming at different speeds vary more on the blasted tool surface than on the other surfaces. It is assumed that local stochastic effects due to asperities cause this effect.

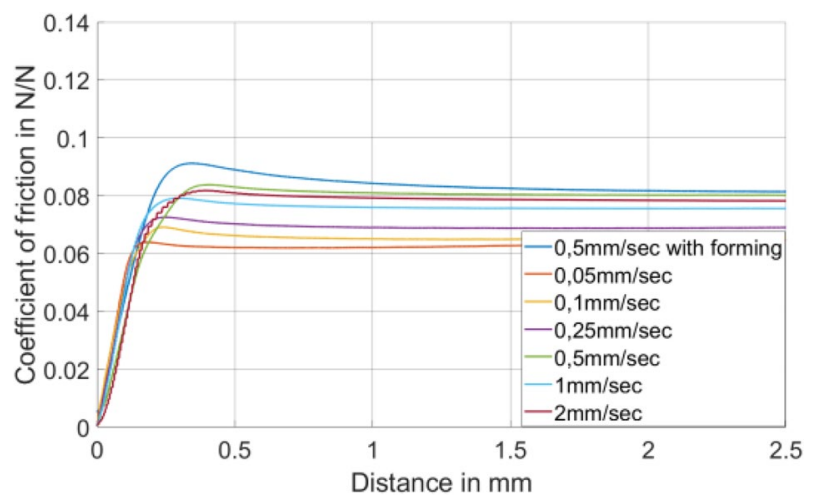

Fig. 12 Change in coefficient of friction to distance with polished surface (velocity controlled, normal force $150 \mathrm{kN}$ )

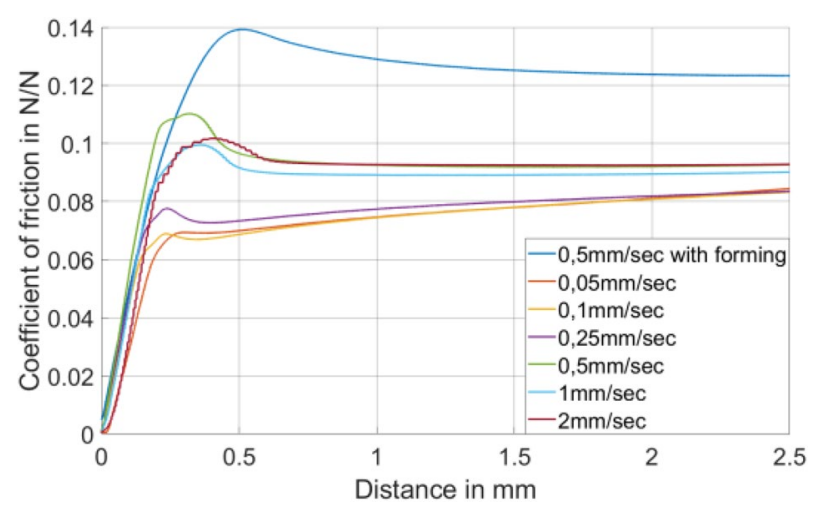

Fig. 13 Change in coefficient of friction to distance with sandblasted surface (velocity controlled, normal force $150 \mathrm{kN}$ ) 


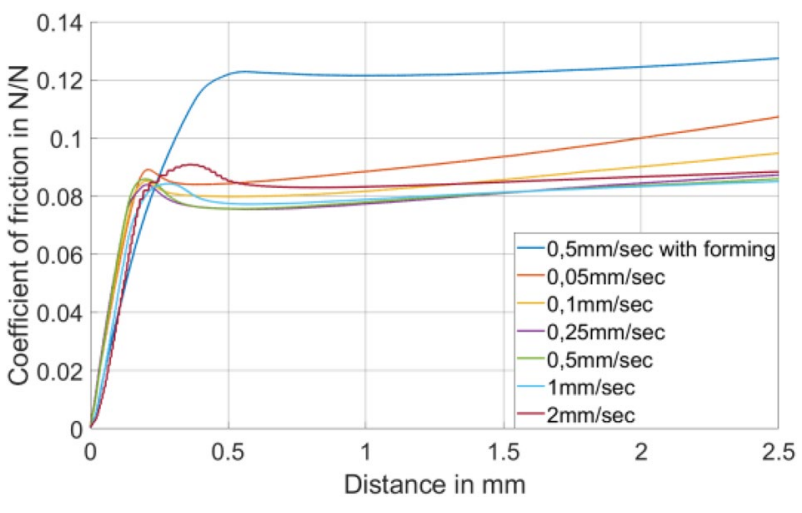

Fig. 14 Change in coefficient of friction to distance with ground surface (velocity controlled, normal force $150 \mathrm{kN}$ )

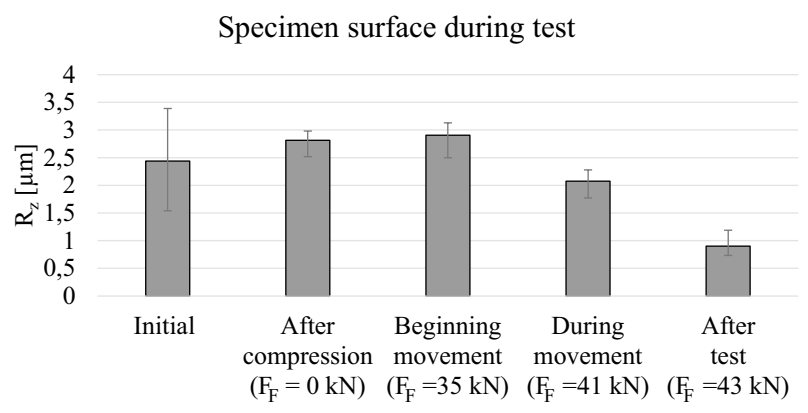

Fig. 15 Surface roughness of the specimen in different states of the test (polished surface, velocity controlled, normal force $150 \mathrm{kN}$ )

It is to be noted that the results of the specimens with polished surface (Fig. 12) show only a very small static friction peak. In the tests with the ground surface, the coefficient of friction even increases after static friction.

\section{Discussion}

In both variants, tests performed with forming result in a higher coefficient of stiction in contrast to the tests executed without forming.

It is plausible that the reason for this is to be found in the surface of the softer friction partner, the specimen. The surface of a specimen is examined for its surface topography immediately after forming, at the beginning of the detachment, and after the experiment, with surface roughness depicted in Fig. 15.

The results show that the surface topography is decreasing to a lower level with increasing sliding distance. Thus, the topography of a specimen is always smoother after an experiment. The lower forces in the tests without forming (see Fig. 8) can be explained with this correlation since the experiments without forming were carried out with specimens that had already undergone an experiment cycle. Therefore, the asperities were already leveled down and the specimens detach earlier.

Additionally, the lack of surface enlargement significantly reduces the thinning of the oil film.

The surface on the tool side also influences the results. While experiments with sandblasted and ground tools result in similar stiction coefficients, the polished surface shows lower coefficients of friction. Based on the observation of the surface smoothening, the surface of the tool could be pressed in the surface of the softer work piece material. Therefore, the experiments performed with rougher tool material result in a rougher specimen surface after forming.

The experiments show that the static friction peak has a negligible influence for smooth tools under the conditions investigated, which are motivated by the oscillating gear forming process. This kind of tools and similar loads can be found also in cold forging or sheet metal forming. Especially for oscillating forming operations, the stiction peak should not be a major influence for the friction condition. The contact area between work piece and tool, which is affected by static friction during forward and return stroke, is the calibration zone. As the change of direction takes place on this formed surface, no substantial smoothening effects of the asperities will affect the tribological system.

These findings apply only to short-term contact and must not be extrapolated to much longer times.

\section{Outlook and Summary}

After a detailed presentation of the state of the art, the paper presents a method for investigating static friction under high normal stresses, as is common in the field of forming technology. In addition, the levelling that occurs during detachment was investigated. When observing the acting stresses, it can be assumed that the energy required for this makes the difference between static friction and sliding friction. The results also indicate that oscillating forming processes are only slightly influenced by static friction.

In upcoming experiments, other lubricants, especially solid lubricants, which are increasingly being used in cold forming, will be tested on the test bench.

Acknowledgements The authors express their thanks to Dr.-Ing. Philipp Kramer and his supervised students, who were heavily involved in the development of the static friction test stand. The investigations presented in this paper were carried out within the research project IGF-20830N 'Tribology of ejection processes'. The authors wish to thank the German Federation of Industrial Research Associations (AiF) and the Federal Ministry for Economic Affairs and Energy (BMWi) for supporting the project IGF $20830 \mathrm{~N}$. 
Funding Open Access funding enabled and organized by Projekt DEAL.

Open Access This article is licensed under a Creative Commons Attribution 4.0 International License, which permits use, sharing, adaptation, distribution and reproduction in any medium or format, as long as you give appropriate credit to the original author(s) and the source, provide a link to the Creative Commons licence, and indicate if changes were made. The images or other third party material in this article are included in the article's Creative Commons licence, unless indicated otherwise in a credit line to the material. If material is not included in the article's Creative Commons licence and your intended use is not permitted by statutory regulation or exceeds the permitted use, you will need to obtain permission directly from the copyright holder. To view a copy of this licence, visit http://creativecommons.org/licenses/by/4.0/.

\section{References}

1. Menezes, P.L., Kumar, K., Kishore, Kailas, S.V.: Influence of friction during forming processes - a study using a numerical simulation technique. Int. J. Adv. Manuf. Technol. 40(1112), 1067-1076 (2009). https://doi.org/10.1007/s00170-008-1425-5

2. Pitenis, A., Dowson, D., Gregory Sawyer, W.: Leonardo da vinci's friction experiments: An old story acknowledged and repeated. Tribol. Lett. 56(3), 509-515 (2014). https://doi.org/10.1007/ s11249-014-0428-7

3. Kardan, I., Kabganian, M., Abiri, R., Bagheri, M.: Stick-slip conditions in the general motion of a planar rigid body. J. Mech. Sci. Technol. 27(9), 2577-2583 (2013). https://doi.org/10.1007/ s12206-013-0701-y

4. Schmidt, W., Groche, P.: Wear prediction for oscillating gear forming processes using numerical methods. Key Eng. Mater. 767,
283-289 (2018). https://doi.org/10.4028/www.scientific.net/KEM. 767.283

5. Schmidt, W., Heß, B., Groche, P.: Investigation of the tribological conditions in forming gears with oscillating ram movements. In: Proceedings of the 7th International Conference on Tribology in Manufacturing (2016)

6. Groche, P., Schmidt, W.: Wear prediction in oscillating cold forging processes. Tribol. Lett. 68(4), 651 (2020). https://doi.org/10. 1007/s11249-020-01367-w

7. Tabor, D.: Friction-The present state of our understanding. J. Lubr. Technol. 103(2), 169-179 (1981). https://doi.org/10.1115/1. 3251622

8. Bay, N., Wanheim, T.: Real area of contact and friction stress at high pressure sliding contact. Wear 38(2), 201-209 (1976). https://doi.org/10.1016/0043-1648(76)90069-7

9. Chang, W.R., Etsion, I., Bogy, D.B.: Static friction coefficient model for metallic rough surfaces. J. Tribol. 110(1), 57-63 (1988). https://doi.org/10.1115/1.3261575

10. Rabinowicz, E.: The determination of the compatibility of metals through static friction tests. ASLE Trans. 14(3), 198-205 (2016). https://doi.org/10.1080/05698197108983243

11. Hurtado, J.F., Melkote, S.N.: Workpiece-fixture static friction under dynamic loading. Wear 231(1), 139-152 (1999). https:// doi.org/10.1016/S0043-1648(99)00123-4

12. Hanaor, D.A., Gan, Y., Einav, I.: Static friction at fractal interfaces. Tribol. Int. 93, 229-238 (2016). https://doi.org/10.1016/j. triboint.2015.09.016

13. Groche, P., Stahlmann, J., Müller, C.: Mechanical conditions in bulk metal forming tribometers-Part two. Tribol. Int. 66(2270), 345-351 (2013). https://doi.org/10.1016/j.triboint.2012.11.028

Publisher's Note Springer Nature remains neutral with regard to jurisdictional claims in published maps and institutional affiliations. 